\title{
What is a Global Environmental Pollution Problem?
}

\author{
J. T. Trevors
}

Published online: 4 February 2010

(C) Springer Science+Business Media B.V. 2010

Global environmental pollution problems are not just problems that affect many people. Instead, they are those immense problems that affect the entire planet Earth. These problems may or may not affect all people at the same time, nor to the same level. Global environmental pollution problems may have commenced many decades or centuries ago and are the result of additive, interconnected events that are manifested in a more complex present-day problem. It may also be true that the problem was generated at a relatively simple level of complexity but evolved into a more complex problem, requiring a complex solution. An excellent example of this type of global pollution problem is global climate change which is complex, requires the cooperation of all countries, and makes our human society and all living organisms vulnerable. Global climate change is really the sum of all pollution combined with natural changes in climate. Global problems are also problems where solutions may not be immediate and involve complex political, social, and economic components. Some humans will be resistant to change, cannot imagine the consequences, insist their values are correct, and may have constrained ideological, cultural, and political values and ideas. This is all occurring in a

J. T. Trevors $(\bowtie)$

School of Environmental Sciences, University of Guelph,

Guelph, ON, Canada, N1G 2W1

e-mail: jtrevors@uoguelph.ca time of globalization - in increased interconnectedness among countries in the areas of economics, trade, culture, and politics.

It was not raining when Noah built the ark. Humans have the capacity to think ahead, plan, anticipate, predict, and be prepared. The future of humanity lies in anticipating and preventing global problems while fixing our existing problems at the local, national, and global levels. Of course, this is an immense challenge to humans because we disagree on forms of government, economics, basic human rights, war and conflict versus peace, and the distribution of resources on the planet. Humanity's future is not guaranteed unless all people and all nations strive for a quality of life that is sustainable while managing our current climate change crisis and at the same time reducing human population growth and implementing conservation policies worldwide. This may seem like a utopian wish as we enter another decade with too many humans subjected to poverty, hunger, conflicts, wars, uneven distribution of resources, lack of universal basic human rights and needs, lack of education, potable water, public health, pandemics, transportation and communication infrastructure, discrimination, racism, religious intolerance, greed, power, dictatorships, unstable governments, a multitude of national and international security issues, and no legally binding agreement on climate change for countries. The list is not complete, but the point has been made. 
In the past, an immense amount of effort was devoted to solving or remediating existing problems. Today, we have the capacity to predict many problems or changes. Science, engineering, and technology have enabled us to have immense predictive powers. Therefore, our capacity for insight and visionary thinking increases as more information is translated into knowledge. Visionary thinking is essential if we are to determine how humans share our planet, share our humanity, and share a common rulebook to prevent further damage to our biosphere. Visionary thinking and problem solving are necessary because climate change is an interlinked and complex problem with unrecognized outcomes. It may be that some proposed and attempted solutions are incorrect. Interconnected problems make solutions more difficult. One could even suggest that the most important environmental problem is deciding what is the most important environmental problem.
However humanity decides to solve global climate change, it will involve information systems that will lead to entirely new disciplines and fields of knowledge. This will spawn new industries and hopefully a better sharing of resources in our common, shared, singular biosphere. Hopefully, there will be another renaissance in thinking, education, innovation, research, and cooperation for humanity. If you enjoy problem solving, thinking, education, humanities, laws, computing and information systems, policy formation and implementation, and innovation and research, then use your skills and expertise to solve the most critical global problems - some of which were mentioned in this article. We also look forward to articles being submitted to this journal that assist in solutions to any environmental problem of significance. The point is-be successful at meaningful activities in research, not trivial ones. 